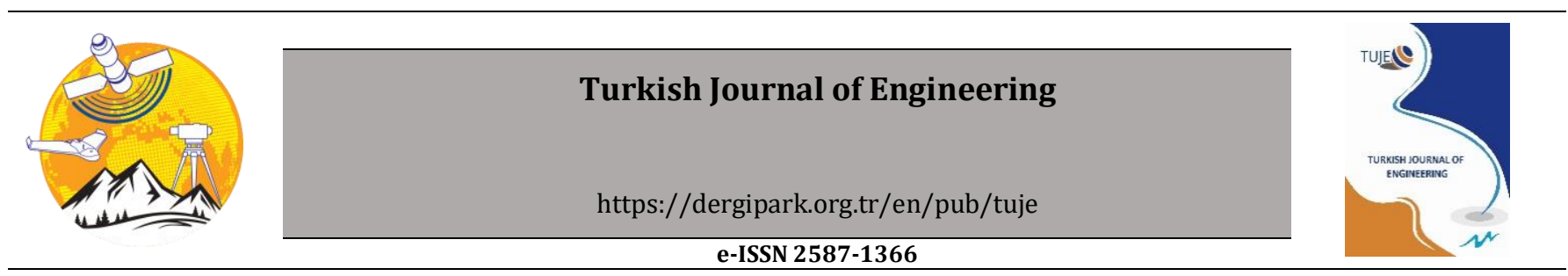

\title{
Cantilever piles or well foundations in supporting temporary deep excavations: comparison of performance, safety and cost
}

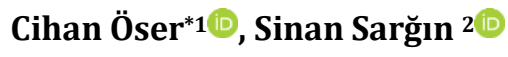 \\ ${ }^{1}$ Istanbul University, Cerrahpaşa Faculty of Engineering, Department of Civil Engineering, Istanbul, Turkey
}

\author{
Keywords \\ Deep excavation \\ Cantilever piles \\ Well foundation \\ Finite element method \\ Cost-Safety-Performance
}

\begin{abstract}
Due to the increasing population in the metropolitans, the construction of the high-rise buildings and shopping malls etc. has rapidly increased for last three decades. Therefore, especially in the city centers, the area of the construction sites has become very limited. Moreover, the requirements such as high bearing capacity of the soils beneath the skyscrapers and the parking area for the vehicles makes the application of the deep excavations essential. It is well-known that designing both safe and economical retaining structures in cohessionless soils such as sands and gravels or silty-clayey mixtures of them is still a challenging issue in geotechnical engineering discipline. Under that circumstances, the construction of two types of the retaining structures frequently comes into the minds: cantilever piles and well foundations. These retaining systems should be designed not only to be resist against failure but also to meet safety requirements for existing buildings and infrastructures near the site until the active forces, which are induced by the soil mass, are supported by the structural elements of the superstructures. In addition to this, the horizontal deformations along the retaining structures should be less than the limits defined by the specifications and the structural codes. In this study, the performances and costs of the both cantilever piles and well foundations in different excavation heights are compared parametrically. For this purpose, a benchmark sandy soil profile given in the literature and the retaining systems are modeled in 2D by using finite elements method. Furthermore, in order to determine the internal forces based reinforced concrete design and the unit costs; a well-known commercial software is used. The promising results of this study could guide to the design engineers in practice for selecting safer and more economical systems within engineering judgment.
\end{abstract}

\section{INTRODUCTION}

Population growth in urban areas cause requirement of new housing, working places, parking lots, etc. construction. The mentioned new construction works cause many problems. Especially during the construction of new buildings in a limited number of empty spaces in big cities, collapses can be occurred due to deep excavations. Due to these collapses, major damages may occur in the surrounding buildings and infrastructure facilities as well as loss of life and property (Bian and Huang 2006; Boone 1996; Laefer et al. 2009; Leisenring 2012; Liu and Wang 2009; Wang and Xu 2010).

Deep excavations are made to go down to the required foundation level in case of encountering thick fill layers near to surface or soils with low bearing capacity. Deep excavations are also made to construct underground parking lots and basement floors for buildings. For this reason, retaining structures are constructed in order to preserve the stability of excavation surfaces and to prevent the lateral ground displacements

The most important factors in the design of retaining structures, which are designed to be temporary or permanent according to the serviceability time, are defining the soil profile as representing the whole construction site, determining the soil parameters in accordance with the design criteria and determining the ground water level correctly. In temporary retaining structures which are designed to hold the excavation until the basement curtain walls of the superstructure 
are constructed, it is aimed to finish the construction of superstructure in a short period of time. In this case, effect of dynamic loads (i.e. earthquake) are not taken into account in the design of retaining structures. However, in projects where the excavation surfaces will remain open for a long time, additional dynamic effects will be carried by the retaining structures in case of possible earthquakes. In such projects, retaining structures are designed permanently and earthquake forces are also taken into account.

Retaining structures may be exposed to excessive displacements due to reasons such as incorrect determination of soil parameters, not modelling of the soil environment properly, not designing the structures with sufficient strength. As a result, general or partial collapse may occur in the retaining structures. For this reason, retaining structures should be designed to be safe against collapse, as well as to make displacements within the permissible limits specified in the regulations not to cause damage at the surrounding structures, roads and infrastructure systems.

Locally in Turkey, cantilever bored piles, ground anchors and well foundations are frequently preferred as retaining systems to support deep excavations in recent years. Within the scope of this study, the advantages and disadvantages of cantilever bored piles and well foundations were revealed, and retaining structures were designed to ensure safety and performance against collapse in a certain sandy soil profile for various excavation depths. In addition, costs have been calculated for the design sections of retaining structures. In this way, comparisons were made in terms of safetyperformance-cost for the two different retaining systems, and it is aimed to guide engineers in their design to choose a safe and economical retaining system.

In this study, three different excavation heights $(\mathrm{H}=8$, 9 and $10 \mathrm{~m}$.) and three different bored pile diameters $(\mathrm{D}=0.65,0.80$ and $1.00 \mathrm{~m}$.) were selected. Plaxis 2D finite element analysis software was used for the displacement calculations of the piles and well foundations. IstCAD software, which is frequently used for the design of retaining structures in our country, was preferred by the authors for the reinforced calculations and cost calculations of the bored piles and well foundations.

Within the scope of this parametric study, Costs for constructing bored piles and well foundations were considered depending on the unit costs list announced by Republic of Turkey, Ministry of Environment and Urbanization.

\section{METHOD}

Cantilever bored piles and well foundations were selected by the authors as temporary retaining structures to compare the systems in terms of safetyperformance and cost. In the analysis, 8, 9 and 10 meters of excavation heights were selected. The reason for limiting the excavation height to 10 meters is that, construction of cantilever piles for higher excavations would not be applicable for engineering criteria. Also three different diameters for bored piles are used $(D=0.65,0.80$ and 1.00 m.). Smaller diameters $(D<0.65$ $\mathrm{m}$.) for piles are described as mini-piles and they are not suitable for deep excavations. Moreover, bigger and stronger drilling machines are required for greater diameters (D>1.00 m.) and this is not economical and suitable in city centers.

\subsection{Determination of the dimensions}

Required embedded lengths of bored piles are calculated by using Eq. 1 depending on excavation height and shear strength angle $(\phi)$ as given in Gajan (2011).

$$
\frac{d}{H}=(F S)^{0.25} \cdot\left[\left(\frac{K_{p}^{2}}{F S}\right)^{0.17}-1\right]^{-1}
$$

In Eq. 1, dimensional properties of piles are not taken into consideration and only excavation height $(\mathrm{H})$, factor of safety (FS) and passive earth pressure coefficient $\left(\mathrm{K}_{\mathrm{p}}\right)$ are used. Passive earth pressure coefficient $\left(K_{p}\right)$ for the selected soil profile is calculated by using Eq. 2 (Bowles, 1997).

$$
K_{p}=\frac{\sin ^{2}(\alpha-\phi)}{\sin ^{2} \alpha \cdot \sin (\alpha+\delta)\left[1-\sqrt{\frac{\sin (\phi+\delta) \cdot \sin (\phi+\beta)}{\sin (\alpha+\delta) \cdot \sin (\alpha+\beta)}}\right]^{2}}
$$

In Eq. 2:

$\alpha$ : the angle between the wall back surface and the base of the wall $\left(\alpha=90^{\circ}\right.$ in this problem)

$\delta$ : friction angle between the soil and the wall $(\delta=3 / 4 \phi)$

$\beta$ : the angle of inclination of the ground surface behind the wall relative to the horizontal plane $\left(\beta=0^{\circ}\right)$

The passive earth pressure coefficient was calculated as $K_{p}=8.952$ for the soil profile selected within the scope of the study and whose features are given in Section 2.3.

The dimensional properties of cantilever bored piles and well foundations were determined according to the passive earth pressure coefficient $\left(K_{p}\right)$ value, excavation heights (Hexcavation) and factor of safety (FS) values as described in the following sections.

\subsubsection{Bored piles}

The diameters of the bored piles were selected as $\phi 65 \mathrm{~cm}, \phi 80 \mathrm{~cm}$ and $\phi 100 \mathrm{~cm}$ in the study. Embedded lengths of piles were calculated as given in Table 1 by using Eq. 1 for various factor of safety values (with an increase of 0.1 between $\mathrm{FS}=1$ and $\mathrm{FS}=2$ ).

In the design of the retaining system with cantilever bored piles, it has been accepted that the piles will be constructed adjacent and there is no gap between the piles in order to prevent the soil flowing through piles for sandy soil profile. Another reason for the contiguous design of the piles is that the piles will displaced like a wall similar to the well foundations and with this similarity a suitable comparison can be done. 
Table 1. Embedded length of piles

\begin{tabular}{|c|c|c|c|}
\hline \multirow{2}{*}{$\begin{array}{c}\text { Factor of } \\
\text { Safety } \\
\text { (FS) }\end{array}$} & \multicolumn{3}{|c|}{ Socket length of piles ( $\left.\mathrm{L}_{\text {socket }}\right)(\mathrm{m})$} \\
\hline & $\begin{array}{c}\mathrm{H}_{\text {excavation }} \\
8 \mathrm{~m}\end{array}$ & $\begin{array}{c}\mathrm{H}_{\text {excavation }} \\
9 \mathrm{~m}\end{array}$ & $\begin{array}{c}\mathrm{H}_{\text {excavation }} \\
10 \mathrm{~m}\end{array}$ \\
\hline 1.0 & 7.2 & 8.1 & 9.0 \\
\hline 1.1 & 7.6 & 8.6 & 9.5 \\
\hline 1.2 & 8.0 & 9.0 & 10.0 \\
\hline 1.3 & 8.4 & 9.5 & 10.5 \\
\hline 1.4 & 8.8 & 9.9 & 11.1 \\
\hline 1.5 & 9.2 & 10.3 & 11.4 \\
\hline 1.6 & 9.5 & 10.7 & 11.9 \\
\hline 1.7 & 9.9 & 11.1 & 12.3 \\
\hline 1.8 & 10.2 & 11.5 & 12.8 \\
\hline 1.9 & 10.6 & 11.9 & 13.2 \\
\hline 2.0 & 10.9 & 12.3 & 13.6 \\
\hline
\end{tabular}

\subsubsection{Well foundations}

Well foundations are constructed in slabs and within the scope of this study, only a single slab with 3 meters length and 2 meters width was taken into consideration. Foundation width for the well foundations was used as 2 meters that is the width of the slab. In cantilever retaining structures, the critical issue is to satisfy the safety requirements for overturning. For this purpose, foundation depths for well foundations ( $\left.\mathrm{H}_{\text {founadion }}\right)$ were optimized by following the instructions predefined in iSTCAD (2020) software and dimensional properties of well foundations are given in Table 2, depending on the excavation heights and the factor of safety against overturning ( $\mathrm{FS}_{\text {overturning). }}$.

Table 2. Dimensional properties of well foundations

\begin{tabular}{|c|c|c|c|c|c|c|c|}
\hline \multirow{2}{*}{$\begin{array}{c}\text { Factor of } \\
\text { Safety against } \\
\text { overturning } \\
\text { (FS overturning) }\end{array}$} & \multirow[b]{2}{*}{$\begin{array}{l}\text { Foundation } \\
\text { Width } \\
\text { (m) }\end{array}$} & \multicolumn{2}{|c|}{$\mathrm{H}_{\text {excavation }}=8 \mathrm{~m}$} & \multicolumn{2}{|c|}{ Hexcavation $=9 \mathrm{~m}$} & \multicolumn{2}{|c|}{$\mathrm{H}_{\text {excavation }}=10 \mathrm{~m}$} \\
\hline & & $\begin{array}{c}\text { Wall } \\
\text { Thickness } \\
\text { D wall }_{\text {(m) }}\end{array}$ & $\begin{array}{c}\text { Foundation } \\
\text { Depth } \\
\text { Hfoundation }(\mathrm{m})\end{array}$ & $\begin{array}{c}\text { Wall } \\
\text { Thickness } \\
\text { D wall }_{(\mathrm{m})}\end{array}$ & $\begin{array}{c}\text { Foundation } \\
\text { Depth } \\
\text { Hfoundation }(\mathrm{m})\end{array}$ & $\begin{array}{c}\text { Wall } \\
\text { Thickness } \\
\text { D }_{\text {wall }}(\mathrm{m})\end{array}$ & $\begin{array}{c}\text { Foundation } \\
\text { Depth } \\
\text { Hfoundation }(\mathrm{m})\end{array}$ \\
\hline 1.0 & 2.0 & 0.5 & 3.50 & 0.6 & 4.50 & 0.6 & 5.45 \\
\hline 1.2 & 2.0 & 0.5 & 4.40 & 0.6 & 5.40 & 0.6 & 6.45 \\
\hline 1.4 & 2.0 & 0.5 & 5.20 & 0.6 & 6.30 & 0.65 & 7.35 \\
\hline 1.5 & 2.0 & 0.5 & 5.60 & 0.6 & 6.70 & 0.65 & 7.80 \\
\hline 1.6 & 2.0 & 0.5 & 6.00 & 0.6 & 7.10 & 0.7 & 8.25 \\
\hline 1.8 & 2.0 & 0.5 & 6.60 & 0.8 & 7.85 & 0.7 & 9.15 \\
\hline 2.0 & 2.0 & 0.5 & 7.30 & 0.8 & 8.70 & 0.8 & 10.00 \\
\hline
\end{tabular}

\subsection{Implemented software}

Two different software were used within the scope of this study for the numerical design and reinforced concrete calculations of bored piles and well foundations. Plaxis 2D (Brinkgreve et al., 2019) software was used for the FEM analysis (finite element method) and displacement calculations of retaining structures. Also iSTCAD (2020) retaining wall software (Göksa, 2020) was used for the reinforced concrete calculations of retaining systems (Figure 1).

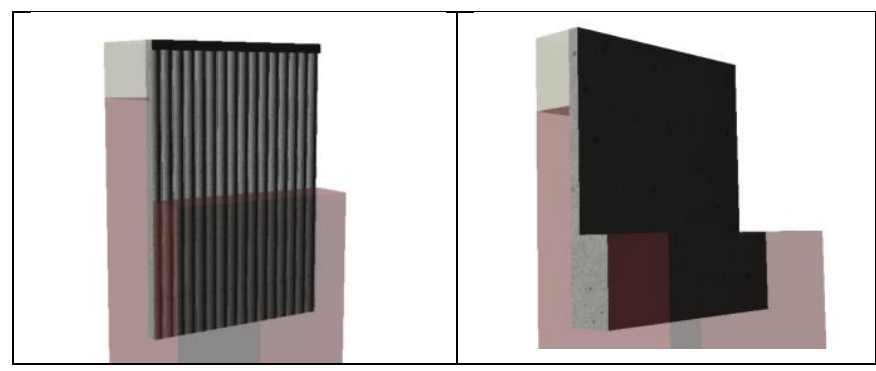

a) Cantilever bored piles

b) well foundations

Figure 1. Screenshots of istCAD software

\subsection{Numerical Modeling with Finite Element Methods}

\subsubsection{Model mesh and boundary condition}

One of the main aims of this study is comparing the performance and cost-efficiency of bored pile and well foundations under the same soil conditions. For this purpose, a benchmark soil stratum is selected. A medium-dense sandy soil has a thickness of $27 \mathrm{~m}$. is underlying 3-m-thick silty soil from ground surface. In addition to this, the groundwater level is not defined in the model due to considering the difficulties of excavation of the well foundation under groundwater level in real practice. The soil profile with finite element meshing is shown in Figure 2. There are no interface elements among the periphery, the pile or well foundation and the surrounding soils because the shear strength at the interface between the structural elements and the surrounding soil is higher that of the surrounding sand and silt formation. To ensure that the boundary effect will be minimized, the finite element mesh is extend to a depth of $30 \mathrm{~m}$. and a horizontal length of 100 $\mathrm{m}$. The displacement and rotations in the two directions are restricted at the bottom of the finite element mesh. Furthermore, the displacements in the $\mathrm{x}$ direction of the horizontal boundaries of the model are set zero. The stages of the construction of the both pile and well foundations are followed in the finite-element calculation as tabulated in Table 3 .

\subsubsection{Constitutive models and determined parameters}

The silt and medium dense sand soil layers are modeled as linearly elastic to perfectly plastic materials with the Mohr-Coulomb model (MC). The constitutive models controlling the stress-strain behavior of the soil 
and regarding stiffness and strength parameters are summarized in Table 4.

The bored piles and the well foundation are modeled as linear elastic (LE) model with structural elements which allows to users determine internal forces and displacements of a pile or wall. The properties of structural elements are given in Table 5.

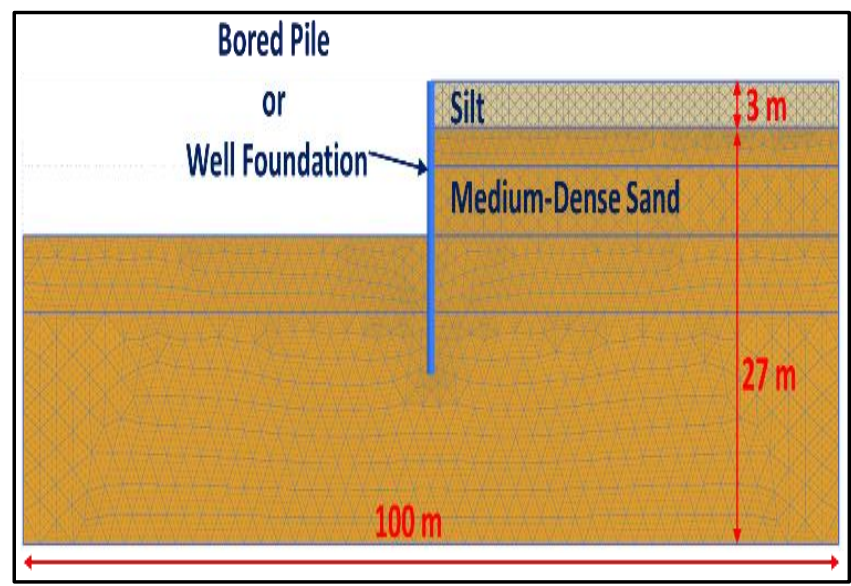

Table 3. Construction stages in the FEM calculation

\begin{tabular}{ll}
\hline Stages & \multicolumn{1}{c}{ Explanation } \\
\hline 0 & Generation of the initial stresses (Gravity loading) \\
1 & Installation of the pile or well foundation \\
2 & Excavation of a 3.0-m-high soil \\
3 & Excavation of a 3.0-m-high soil \\
4 & Excavation of the soil until required depth \\
\hline
\end{tabular}

Table 4. Parameters used in MC model

\begin{tabular}{lcc}
\hline Parameters & Silt & Medium Dense Sand \\
\hline Unit weight, $\gamma\left(\mathrm{kN} / \mathrm{m}^{3}\right)$ & 16 & 18 \\
Elastic modulus, $E^{\prime}(\mathrm{MPa})$ & 90 & 135 \\
Poisson's ratio, $v^{\prime}$ & 0.3 & 0.3 \\
Cohesion, $c(\mathrm{kPa})$ & 5 & - \\
Friction angle, $\varnothing\left(^{\circ}\right)$ & 30 & 34 \\
Dilatancy angle, $\psi\left(^{\circ}\right)$ & - & 3 \\
Permeability Coeff., & 0.59 & 0.98 \\
$\mathrm{k}(\mathrm{m} /$ day) & Drained & Drained \\
Material behavior & & \\
\hline
\end{tabular}

Figure 2. Finite element model of the problem

Table 5. Parameters used in LE model

\begin{tabular}{|c|c|c|c|c|c|c|c|c|c|}
\hline \multirow[t]{2}{*}{ Parameters } & \multicolumn{6}{|c|}{ Cross-sections width of the walls in well foundation, $\mathrm{H}(\mathrm{cm})$} & \multicolumn{3}{|c|}{$\begin{array}{l}\text { Diameters of the bored piles, } \\
\mathrm{D}(\mathrm{cm})\end{array}$} \\
\hline & 50 & 60 & 65 & 70 & 80 & $\begin{array}{c}\text { Base } \\
(\mathrm{H}=200 \mathrm{~cm})\end{array}$ & 65 & 80 & 100 \\
\hline $\begin{array}{l}\text { Unit weight, } \\
\gamma\left(\mathrm{kN} / \mathrm{m}^{3}\right)\end{array}$ & 24 & 24 & 24 & 24 & 24 & 24 & 24 & 24 & 24 \\
\hline $\begin{array}{l}\text { Axial stiffness, } \\
E A(\mathrm{kN} / \mathrm{m})\end{array}$ & $14 \times 10^{6}$ & $16.8 \times 10^{6}$ & $18.2 \times 10^{6}$ & $19.6 \times 10^{6}$ & $22.4 \times 10^{6}$ & $56 \times 10^{6}$ & $14.3 \times 10^{6}$ & $17 \times 10^{6}$ & $21.9 \times 10^{6}$ \\
\hline $\begin{array}{l}\text { Bending stiffness, } \\
E I\left(\mathrm{kNm}^{2} / \mathrm{m}\right)\end{array}$ & $292 \times 10^{3}$ & $504 \times 10^{3}$ & $605 \times 10^{3}$ & $800.3 \times 10^{3}$ & $1195 \times 10^{3}$ & $1867 \times 10^{3}$ & $377 \times 10^{3}$ & $703 \times 10^{3}$ & $1375 \times 10^{3}$ \\
\hline Poisson's ratio, $v^{\prime}$ & 0.2 & 0.2 & 0.2 & 0.2 & 0.2 & 0.2 & 0.2 & 0.2 & 0.2 \\
\hline
\end{tabular}

\subsection{Determination of the modulus of subgrade reaction for deeper soil}

In general, finite elements and finite differences, numerical methods have solutions considering the stiffness of both soil and structural members. On the other hand, early methods are based on the numerical solution of the forth order differential equation. The foundation of any buildings is considered as a linear elastic structural element whose soil reaction is replaced by an infinite number of independent linear elastic springs following the Winkler (1867) hypothesis. The mechanical constant of these springs represents the modulus of subgrade reaction for soils can be defined, as the pressure required producing a unit settlement (Figure 3a).

The numerical model developed in IstCAD software to determine the design requirements of the reinforced concrete bored piles needs subgrade modulus of the soil in order to take into account effect of the soil that the piles are socketed. The subgrade modulus could be defined in the software by a constant value and found in the literature for a granular soils. Although, there are lots of references (Biot, 1937; Terzaghi, 1955; Vesic, 1961; Meyerhoff and Baike, 1963; Selvadurai, and Gladwell 1980; Bowles, 1997) which are useful for determining the subgrade modulus, these values given in Table 6 belong to the specific soils and the range of them are doubtfully wide.

Table 6. Modulus of subgrade reaction for specific soil types (Bowles, 1997)

\begin{tabular}{|c|c|}
\hline Soil Type & $\begin{array}{l}\text { Modulus of Subgrade } \\
\text { Reaction, } \mathrm{k}_{\mathrm{s}}\left(\mathrm{kN} / \mathrm{m}^{3}\right)\end{array}$ \\
\hline Loose sand & $4.8 \times 10^{3}-16 \times 10^{3}$ \\
\hline Medium dense sand & $9.6 \times 10^{3}-80 \times 10^{3}$ \\
\hline Dense sand & $64 \times 10^{3}-128 \times 10^{3}$ \\
\hline Clayey medium dense sand & $32 \times 10^{3}-80 \times 10^{3}$ \\
\hline Silty medium dense sand & $24 \times 10^{3}-48 \times 10^{3}$ \\
\hline \multicolumn{2}{|l|}{ Clayey soil } \\
\hline $\mathrm{qa} \leq 200 \mathrm{kPa}$ & $12 \times 10^{3}-24 \times 10^{3}$ \\
\hline $\mathrm{qa} \leq 800 \mathrm{kPa}$ & $24 \times 10^{3}-48 \times 10^{3}$ \\
\hline $\mathrm{qa}>800 \mathrm{kPa}$ & $>48 \times 10^{3}$ \\
\hline
\end{tabular}

For this purpose, the single pile and surrounding soil stratum is modeled numerically in PLAXIS 2D V20 software (Brinkgreve et al., 2019). The details of the soil properties and constitutive models are given in previous section.

In PLAXIS 2D, the load (stress)-displacement history of any FEM points could be saved for both construction and loading stages of any geotechnical structures. 


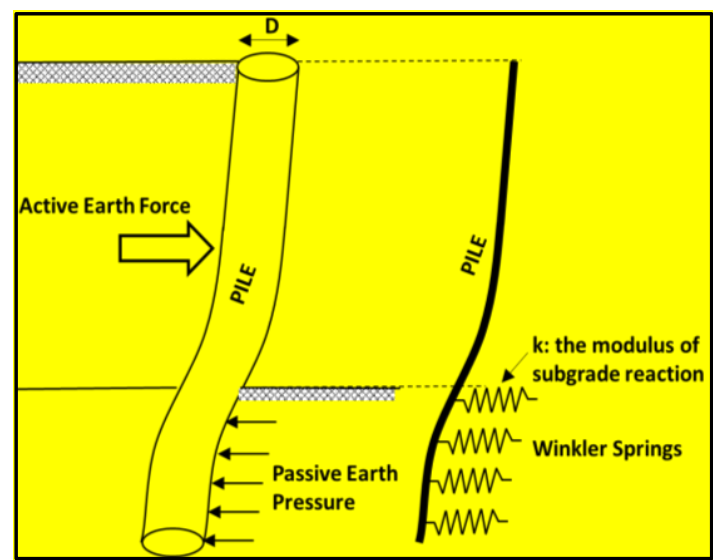

a) Schematic explanation of modulus of subgrade reaction

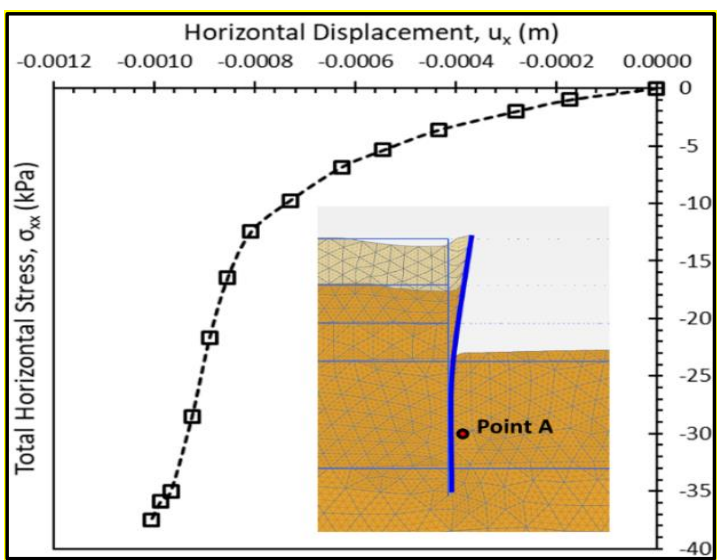

b) Determining the modulus of subgrade reaction

Figure 3. Schematic explanation of modulus of subgrade reaction and determining the modulus of subgrade reaction for the selected soil profile

In this study, a stress point (Point A) is selected and its stress-displacement history is plotted as given in Figure $3 \mathrm{~b}$. The modulus of subgrade reaction could be estimated from stress-displacement curve as $\mathrm{k}_{\mathrm{x}}=15500$ $\mathrm{kN} / \mathrm{m}^{3}$ for deeper soils that the bored pile is socketed. The modulus of subgrade reaction has been determined only for cantilever bored piles, because this parameter is only used as an input data for pile design in iSTCAD (2020).

\section{COST CALCULATIONS}

"2019 Construction and Installation Unit Prices" announced by the Republic of Turkey, Ministry of
Environment and Urbanization was used for the cost calculations of bored piles and well foundations (T.C Çevre ve Şehircilik Bakanlığı, 2019).

In the design, C25/30 concrete class was preferred both for piles and well foundations. Unit prices of reinforced concrete bored piles are given in Table 7. Unit prices of excavation, formwork and concrete pouring were used in the cost calculations of well foundations. The price list of these installations are given in Table 8. It must be noted that, prices of the steel reinforcements are not included in these tables and they are given in Table 9 separately.

Table 7. Unit prices list of bored piles (T.C Çevre ve Şehircilik Bakanlığı, 2019)

\begin{tabular}{|c|c|c|c|c|}
\hline Pose No & $\begin{array}{l}\text { Previous } \\
\text { Pose No }\end{array}$ & Type of Construction/Installation & Unit & $\begin{array}{c}\text { Unit Cost } \\
\text { (TL) }\end{array}$ \\
\hline 15.140 .1103 & Y.16.061/04 & $\begin{array}{l}\text { Constructing cast-in-place reinforced concrete bored piles with } \\
\text { a diameter of } \phi 65 \mathrm{~cm} \text {, with C } 25 / 30 \text { compression strength (length } \\
\text { between } 0.0-18.0 \mathrm{~m}, 18.0 \mathrm{~m} \text { included) }\end{array}$ & $\mathrm{m}$ & 242.63 \\
\hline 15.140.1104 & Y.16.061/05 & $\begin{array}{l}\text { Constructing cast-in-place reinforced concrete bored piles with } \\
\text { a diameter of } \phi 65 \mathrm{~cm} \text {, with C } 25 / 30 \text { compression strength (length } \\
\text { between } 18.01-36.0 \mathrm{~m}, 36 \mathrm{~m} \text { included) }\end{array}$ & $\mathrm{m}$ & 262.78 \\
\hline 15.140.1105 & Y.16.061/06 & $\begin{array}{l}\text { Constructing cast-in-place reinforced concrete bored piles with } \\
\text { a diameter of } \phi 80 \mathrm{~cm} \text {, with } \mathrm{C} 25 / 30 \mathrm{compression} \text { strength (length } \\
\text { between } 0.0-18.0 \mathrm{~m}, 18.0 \mathrm{~m} \text { included) }\end{array}$ & $\mathrm{m}$ & 316.61 \\
\hline 15.140.1106 & Y.16.061/07 & $\begin{array}{l}\text { Constructing cast-in-place reinforced concrete bored piles with } \\
\text { a diameter of } \phi 80 \mathrm{~cm} \text {, with } \mathrm{C} 25 / 30 \mathrm{compression} \text { strength (length } \\
\text { between } 18.01-36.0 \mathrm{~m}, 36 \mathrm{~m} \text { included) }\end{array}$ & $\mathrm{m}$ & 350.20 \\
\hline 15.140 .1107 & Y.16.061/08 & $\begin{array}{l}\text { Constructing cast-in-place reinforced concrete bored piles with } \\
\text { a diameter of } \phi 100 \mathrm{~cm} \text {, with } \mathrm{C} 25 / 30 \text { compression strength } \\
\text { (length between } 0.0-18.0 \mathrm{~m}, 18.0 \mathrm{~m} \text { included) }\end{array}$ & $\mathrm{m}$ & 474.54 \\
\hline 15.140 .1108 & Y.16.061/09 & $\begin{array}{l}\text { Constructing cast-in-place reinforced concrete bored piles with } \\
\text { a diameter of } \phi 100 \mathrm{~cm} \text {, with C25/30 compression strength } \\
\text { (length between } 18.01-36.0 \mathrm{~m}, 36 \mathrm{~m} \text { included) }\end{array}$ & $\mathrm{m}$ & 534.55 \\
\hline
\end{tabular}

Table 8. Unit prices list of well foundations (T.C Çevre ve Șehircilik Bakanlığı, 2019)

\begin{tabular}{llllc}
\hline Pose No & $\begin{array}{l}\text { Previous } \\
\text { Pose No }\end{array}$ & Type of Construction/Installation & Unit & $\begin{array}{l}\text { Unit Cost } \\
\text { (TL) }\end{array}$ \\
\hline 15.150.1005 & Y.16.050/15 & $\begin{array}{l}\text { Pouring mixed concrete with C25/30 compression strength, in } \\
\text { gray color, produced or purchased in the concrete plant and } \\
\text { poured with concrete pump (transportation is included) }\end{array}$ & $\mathrm{m}^{3}$ & 220.11 \\
15.180 .1002 & Y.21.001/02 & $\begin{array}{l}\text { Manufacturing reinforced concrete form from wood } \\
\text { Narrow deep excavation by hand in soft and hard soil at any } \\
\text { depth (loose and organic soils, loose silt, sand, clay, silty, sand } \\
\text { and soft clay, clayey sand and gravel, and similar soils that can } \\
\text { be shoveled) }\end{array}$ & $\mathrm{m}^{2}$ & 54.95 \\
\hline
\end{tabular}


Table 9. Unit prices list of steel reinforcement bars (T.C Çevre ve Şehircilik Bakanlığı, 2019)

\begin{tabular}{llllc}
\hline Pose No & $\begin{array}{l}\text { Previous } \\
\text { Pose No }\end{array}$ & Type of Construction/Installation & Unit & $\begin{array}{c}\text { Unit Cost } \\
(\mathrm{TL})\end{array}$ \\
\hline 15.160 .1003 & Y.23.014 & $\begin{array}{l}\phi 8-\phi 12 \mathrm{~mm} \text { ribbed concrete steel bar (cutting, bending and } \\
\text { placing are included) } \\
\phi 14-\phi 28 \text { mm ribbed concrete steel bar (cutting, bending and } \\
\text { placing are included) }\end{array}$ & ton & 4029.78 \\
15.160 .1004 & Y.23.015 & ton & 3965.28 \\
15.160 .1005 & Y.23.015 & $\begin{array}{l}\text { Rending and placing are included) } \\
\text { bending } \phi 28 \mathrm{~mm} \text { (cutting, }\end{array}$ & ton & 3916.65 \\
\hline
\end{tabular}

\section{RESULTS}

The results of the safety-performance and cost comparison, in which the embedded lengths of bored piles with diameter of $\mathrm{D}=65 \mathrm{~cm} ., 80 \mathrm{~cm}$. and $100 \mathrm{~cm}$. are taken into account for the excavation heights of $\mathrm{H}=8 \mathrm{~m}$., $9 \mathrm{~m}$. and $10 \mathrm{~m}$. , are presented in Figure 4 (a)-(c) respectively.

The maximum displacement values at the end of excavation were calculated between $1.25 \mathrm{~cm}$. and $3.0 \mathrm{~cm}$. for the excavation with a height of $8 \mathrm{~m}$. These results appear to be within the permissible displacement limits given in the related deep excavation codes and regulations (Sabatini et al., 1999; BS-EN 1997-1, 2004). Although the number of safety increases, the decrement in the wall displacements are limited as seen in Figure 4 (a). On the other hand, when the safety-cost curve

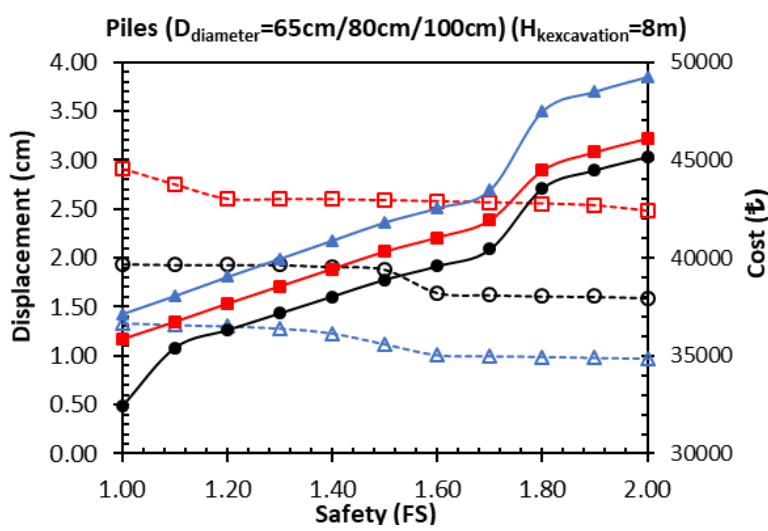

a)

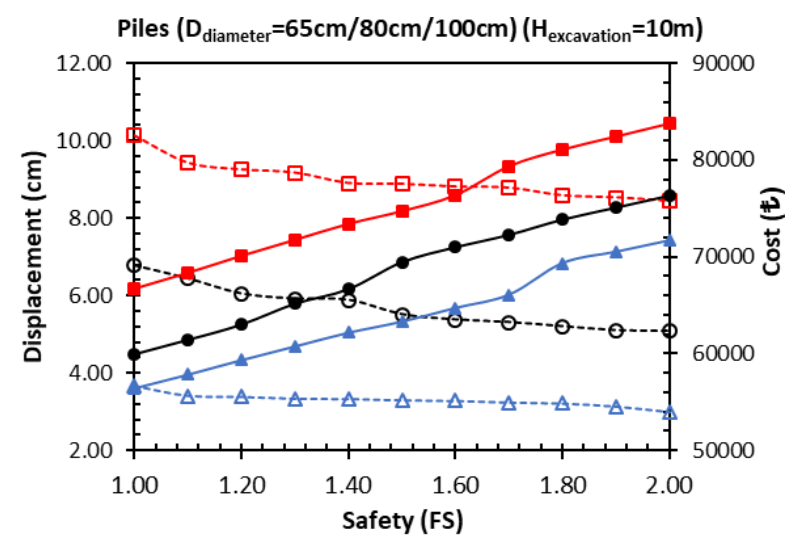

c) examined, it can be seen that the costs increase rapidly if a safer design is made. In addition, considering the minimum amount of reinforcement to be used depending on the constructive rules, it is seen that the costs increase when using bored piles with larger diameters in excavations with relatively low heights. According to Figure 4 (b)-(c), in case the excavation height increases and the diameter of the bored pile decreases, it has been calculated that the predicted horizontal displacements increase considerably. In the same manner, it was concluded that, the costs increased considerably and became uneconomical in order to make safe excavation using bored piles with small diameters. This is because, in piles with small diameters, the cost of reinforcement to be used to compensate the bending moments and shear forces increases approximately 1.5 times.

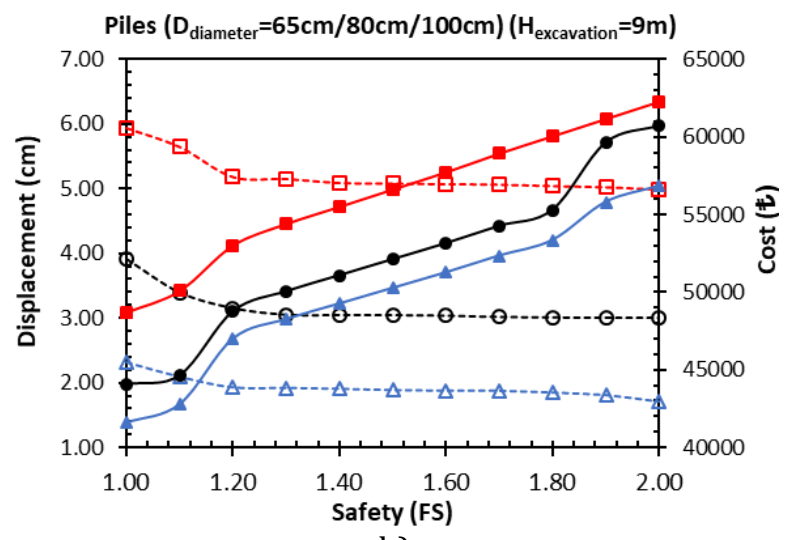

b)

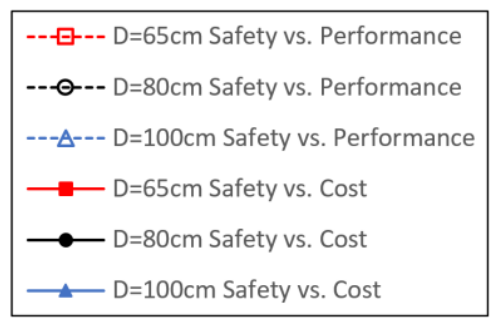

Figure 4. Comparison of the safety-performance-cost efficiency of the cantilever-bored piles for various excavation heights; a) $8 \mathrm{~m}$, b) $9 \mathrm{~m}$, c) $10 \mathrm{~m}$

The performance of the well foundations are more sensitive than cantilever bored piles according to the required safety. In Figure 5 (a), the horizontal displacement estimated by FEM analysis rapidly decrease when the factor of safety is slightly increased from 1.0 to 1.2. If the safety requirements is increased up to $\mathrm{FS}=2.0$, the determined displacement, which is initially ( $F S=1.0$ ) about $5.2 \mathrm{~cm}$ can be less than $1.0 \mathrm{~cm}$. 
On the other hand, the majority of the decrease in horizontal deformation is seen in the range of factor of safety between 1.0 and 1.4. Although the decrease of the horizontal displacement is limited, the costs increase rapidly after that level of the safety. Thus, the wall with the selected thickness seems to be overdesigned if the factor of safety is greater than 1.4 .

The similar trend of both in the horizontal displacements and the costs can be observed for the excavation depth of $9 \mathrm{~m}$. and $10 \mathrm{~m}$. of well foundations in Figure 5 (b) and (c), respectively.

In the analysis of the well foundations, while the height of the excavation remains at the same level (i.e. $\mathrm{H}_{\text {excavation }}=8 \mathrm{~m}$., $9 \mathrm{~m}$. or $10 \mathrm{~m}$.), the foundation depth is increased in order to raise the factor of safety against

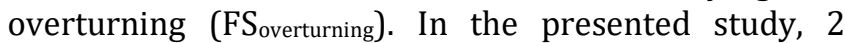
meters wide rigid foundations are used in well foundations. For this reason, deeper foundations are excavated to raise the factor of safety against overturning. Correspondingly, the active earth pressures acting on the wall increase and the displacement values in the cantilever section of the wall increase sensitively. Moreover, structural elements used in Plaxis 2D models have different rigidity properties as seen in Table 2 .

Comparison of the unit costs and horizontal displacements, which are in terms of the performance of both cantilever bored piles and well foundations in

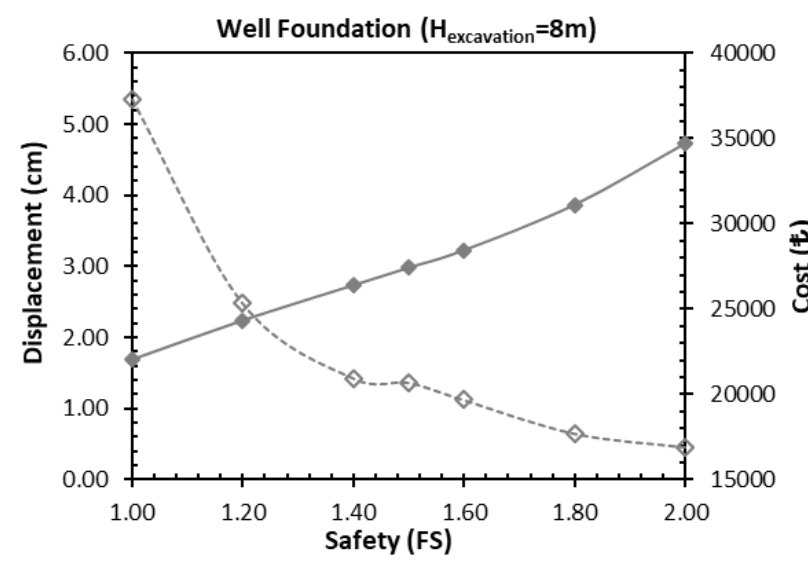

a)

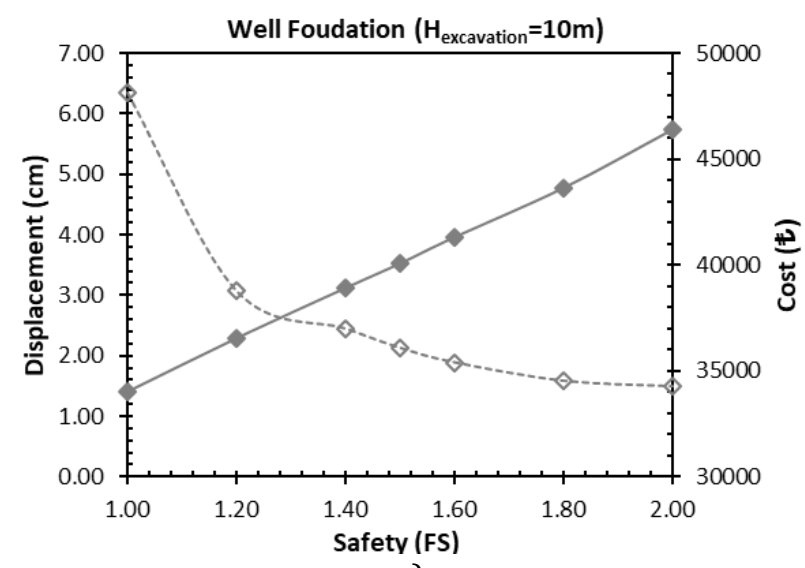

c) excavation depth of $8 \mathrm{~m}$., is presented in Figure 6 (a). Under limit equilibrium condition ( $F S=1.0)$ the displacements of cantilever bored piles and well foundations differs significantly. For instance, while the horizontal displacement of the bored pile $(D=100 \mathrm{~cm}$.) is $1.3 \mathrm{~cm}$, the displacement of the well foundation is about four times greater than the displacement estimated in related bored pile. Furthermore, the displacements calculated from numerical analysis modeled for bored piles with diameters of $80 \mathrm{~cm}$. and $65 \mathrm{~cm}$. are $40 \%$ and $60 \%$ of the displacement belongs to well foundations in the same depth under limit equilibrium condition. However, as the factor of safety rise, the horizontal displacements obtained for the well foundation decrease sharply, the displacements determined for the bored piles remain constant vice versa.

In Figure 6 (b)-(c), the cantilever-bored pile with a diameter of $65 \mathrm{~cm}$. can be evaluated as the most unsafe design in terms of the displacement for $9 \mathrm{~m}$. and $10 \mathrm{~m}$. excavation depth. As the height of excavation increases, the piles with smaller cross sectional area becomes insufficient.

On the other hand, although the displacements calculated for well foundations are approximately same as the predicted displacement of the piles has a diameter of $80 \mathrm{~cm}$., the displacements of the piles has a diameter of $100 \mathrm{~cm}$ were determined smaller.

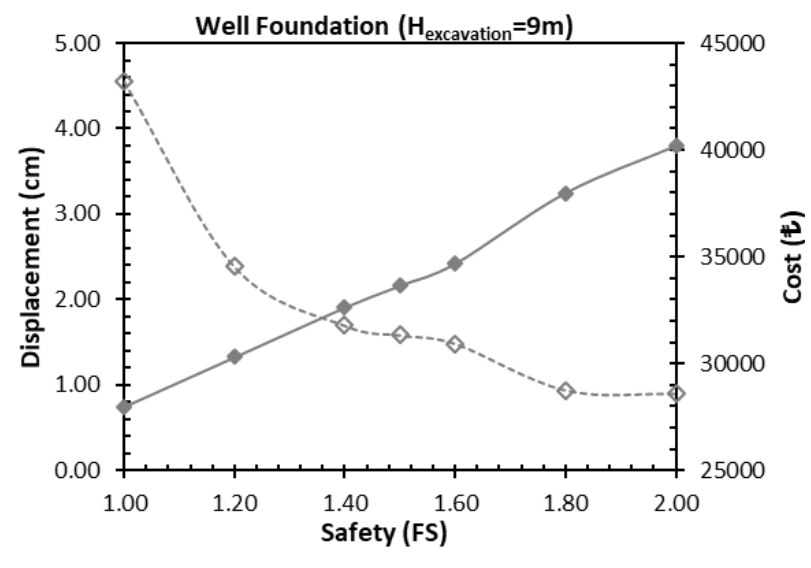

b)

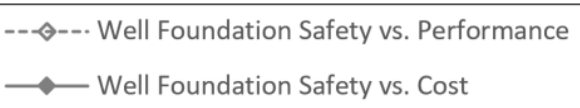

Figure 5. Comparison of the performance/cost efficiency of the well foundations 


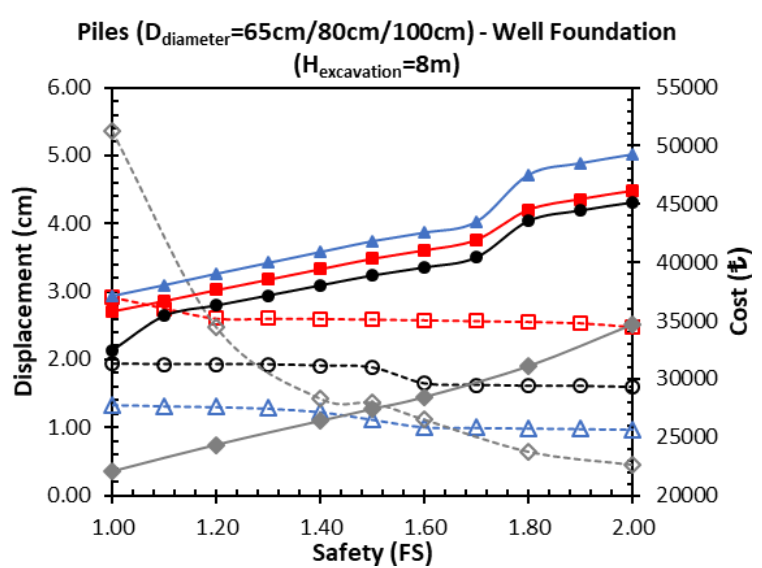

a)

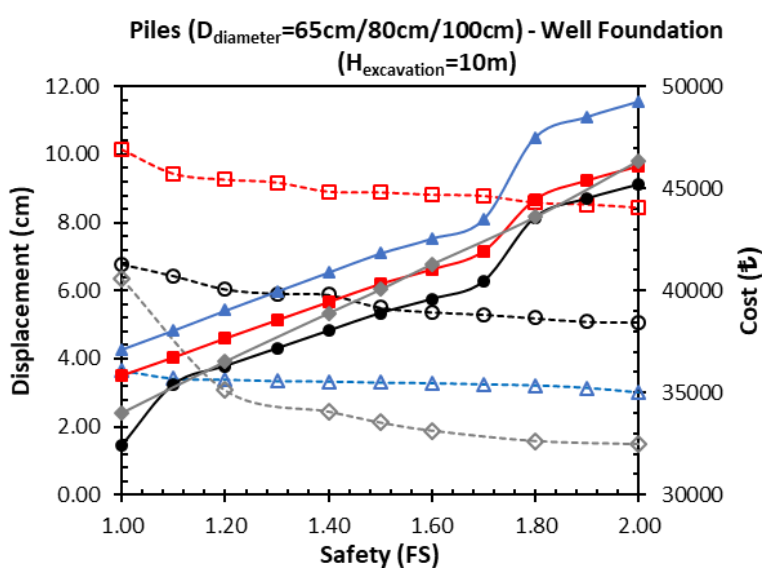

c)

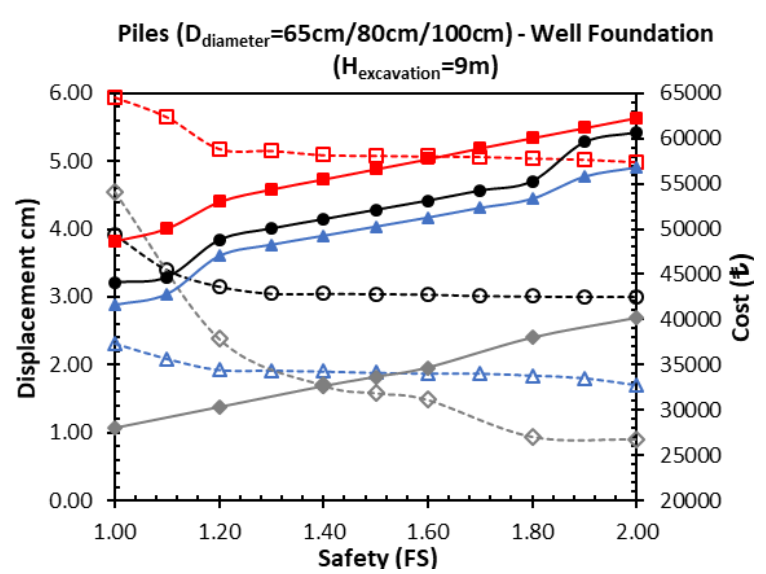

b)

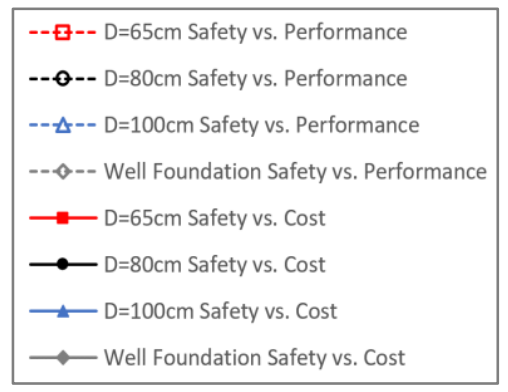

Figure 6. Comparison of the performance/cost efficiency of the well foundation

The costs of the retaining structures analyzed in this study are also compared in Figure 7. It can be easily observed that the costs of well foundations with selected cross sections remain less than the cost of the application of the cantilever-bored piles for 8 and 9 meters excavation height. However, in the 10-meter high excavations; well foundation depth should be increased as shown in Table 2 for safe design. It can be said that this situation increases the well foundation costs significantly and brings them to the same level with the piles ( $D=65$ $\mathrm{cm}$. and $\mathrm{D}=80 \mathrm{~cm}$.).

\section{RECOMMENDATIONS FOR FURTHER STUDIES}

This study is a preliminary study aiming to compare well foundations and cantilever bored piles, which are retaining structures, in terms of performance and cost. It is clear that factors such as the presence of the groundwater, variability of the spacing between bored piles, installation of the anchors or soil nails etc. effect the performance, safety and cost of the design. Further studies in which these factors are also taken into consideration are ongoing.

\section{CONCLUSION}

Within the scope of this study, two different retaining structures, cantilever bored piles and well foundations, are compared in terms of "performancesafety" and "cost-safety" in deep excavations with different heights. For this purpose, a series of numerical analyses based on finite element (FEM) and limit equilibrium (LE) methods conducted.

In order to compare the efficiency of the cantilever bored piles with different diameters ( $D=65,80$ and 100 $\mathrm{cm}$.) for various excavation heights $(\mathrm{H}=8,9$ and $10 \mathrm{~m}$.) the horizontal displacements and the costs are calculated. According to the results, the retaining system constructed with piles has smaller diameter deflects more than the systems including piles with larger diameters. In point of view from cost analysis, in the cantilever piles constructed in the sandy soil profile where the excavation height is 8 meters, it has been observed that the optimum solution is piles has $80 \mathrm{~cm}$. in diameter. As the excavation height rises, the internal forces (especially the bending moment) and accordingly the pile diameters increase, so it can be concluded that the more economical solution is piles has $100 \mathrm{~cm}$. in diameter.

In retaining systems where well foundations are used, the factor of safety for overall stability is determined and the height of the foundations should be increased for safer designs. Accordingly, when the factor of safety increases, the calculated displacements decrease rapidly, in contrast the costs are getting more expensive

Finally, "performance-safety" and "cost-safety" of the two different retaining structure systems are compared. It can be concluded that, by the increment of the factor of safety numbers, performance of the well foundations improves, thus the horizontal displacements rapidly reduce. On the other hand, the reduction of the 
displacements at the bored piles are negligible. Even though, the costs of the well foundation reach almost the same level with cantilever bored piles at 10 meters excavation height in sandy soil profile, it can be said that well foundations are generally more economical than cantilever bored piles.

\section{Author contributions}

Cihan Öser: conceived of the presented idea, developed the theory, write and edit the manuscript; Sinan Sarğın: performed the computations and verified both the analytical and numerical methods.

\section{Conflicts of interest}

The authors declare no conflicts of interest.

\section{REFERENCES}

Bian Y H \& Huang H W (2006). Fuzzy fault tree analysis of failure probability of SMW retaining structures in deep excavations. GeoShanghai International Conference 2006, 312-319. doi: $10.1061 / 40867(199) 38$

Biot M (1937). Bending of an infinite beam on an elastic foundation. Journal of Applied Mechanics, 203, 1-7.

Boone S J (1996). Ground-Movement-Related Building Damage. Journal of Geotechnical Engineering, 122, (11), 886-896, doi: 10.1061/(asce)07339410(1996)122:11(886)

Bowles J E (1997). Foundation Analysis and Design. The McGraw-Hill Companies, Inc., ISBN: 0-07-912247-7

Brinkgreve R B J, Kumarswamy S, Swolfs W M, Zampich L \& Manoj N R (2019). PLAXIS 2D Tutorial Manual CONNECT Edition V20. Plaxis.

BS EN 1997-1:2004 British Standard. (2004). Eurocode 7: Geotechnical design - Part 1: General rules. In Journal of Constructional Steel Research.

Gajan S (2011). Normalized relationships for depth of embedment of sheet pile walls and soldier pile walls in cohesionless soils. Soils and Foundations, 51(3), 559-564. doi:10.3208/sandf.51.559
Göksa Mühendislik Yazılım Ltd. Ști. (2020, Aralık 22). istCAD Yeni Deprem Yönetmeliğine Tam Uyumlu Duvar Analiz, Tasarım ve Çizim Programı. www.göksa.com.tr.

Laefer D F, Ceribasi S, Long J H \& Cording E J (2009). Predicting RC Frame Response to ExcavationInduced Settlement. Journal of Geotechnical and Geoenvironmental Engineering, 135(11), 16051619. doi:10.1061/(asce)gt.1943-5606.0000128

Leisenring B R (2012). Damage to adjacent building during construction-Expert investigation. Lanchester: Robson Forensic.

Meyerhoff G G \& Baike L D (1963). Strength of steel culverts sheets bearing against compacted sand backfill. Highway Research Board Proceedings, pp. 1-19

Sabatini P J, Pass D G \& Bachus R (1999). Ground Anchors and Anchored Systems. Geotechnical Engineering Circular No.4, Federal Highway Administration, Publication No. FWA-IF-99-015

Selvadurai, A. P. S., \& Gladwell, G. M. L. (1980). Elastic Analysis of Soil-Foundation Interaction. Journal of Applied Mechanics, 47(1), 219 doi:10.1115/1.3153622

T.C. Çevre ve Şehircilik Bakanlığı (2019). 2019 yılı İnşaat ve Tesisat Birim Fiyatları. Ankara, Turkiye: Yüksek Fen Kurulu Başkanlığı.

Terzaghi K (1955). Evaluation of coefficients of subgrade reaction. Geotechnique, 5(4), 297-326, doi:10.1680/geot.1955.5.4.297

Wang X \& Liu Y (2009). Overview of the assessment on the damage from underground excavating on adjacent buildings. Chinese J. Underground Space Eng., 4, 841-847

Wang W D \& Xu Z H (2010). Simplified analysis method for evaluating excavation-induced damage of adjacent buildings. Journal of Geotechnical Engineering, 32(1), 32-38.

Winkler E (1867). Die Lehre von Elastizat and Festigkeit (on Elasticity and fixity), 182, Prague 